\title{
Health Metaphor in Nigeria Economic Discourse
}

\author{
Tolulope Abisodun Oluremi $(\mathrm{PhD}){ }^{{ }^{*}}{ }^{*}$, Ife Fiyinfolu Ajepe $(\mathrm{PhD})^{2}$ \\ ${ }^{I}$ Osun State University, Osogbo, Nigeria \\ ${ }^{2}$ AfeBabalola University, Ado-Ekiti, Nigeria
}

*Corresponding Authors: Tolulope Abisodun Oluremi (PhD), Osun State University, Osogbo, Nigeria

\begin{abstract}
This paper investigated the effect of health metaphorisation and how it is appropriated by journalists in shaping readers' perception of the Nigerian economy; through insights from Lakoff and Johnson's Conceptual Metaphor theory. Data for the study comprised fifteen purposively sampled articles on the Nigerian economy published between year 2003 and 2006, in three selected Nigerian newspapers: Business Day, The Punch and This Day, which had relevance, wide circulation and adequate reports on economic issues in Nigeria. Analysis reveals two health conceptual metaphors: THE BAD STATE OF THE NIGERIAN ECONOMY IS THE BAD STATE OF A HUMAN BEING and THE NIGERIAN ECONOMY IS A SICK HUMAN BEING. These health metaphors influence readers' perception of the Nigerian economy as a passive entity in need of apposite policy actions and exigent attention. Health metaphor performs multifarious functions in the construction and interpretation of economic issues. It is not an extraordinaire device of genus, but the sequence of motivated cognitive device used by Nigerian journalists in rendering contemporary Nigerian issues.
\end{abstract}

Key words: Health Metaphor, Nigerian Economy, Print media discourse

\section{INTRODUCTION}

Metaphor is a prominent tool of conceptualisation in economic journalism. Different conceptual metaphors have been revealed, analysed and interpreted within economic journalism (mainly from the prints). In particular, metaphor interrogations have accentuated the rifeness of conceptual domains (such as marriage, journey, war/combat, health, building, sports, liquid, ferocious animal) in framing specific targets in economic discourse on issues such as business acquisition, finance, inflation, marketing, banking/money, among others, of several countries (see Boers 1997, Koller 2003, White 2003, Charteris-Black 2004, Chow 2010, Silaski \& Durovic 2010, Silaski \& Kilyeni 2011, Tomoni 2012, Song 2013, and others). However, for Nigeria, adequate scholarly attention has not been accorded metaphor investigation in economic discourse in the country. As Kövecses (2005:239) rightly reaffirms, "people will make more extensive use of a source domain when that particular source domain becomes more salient for them under certain circumstance". There are several conceptual domains that may be examined in Nigeria economic discourse, but the notion of health conceptual domain requires special attention taking into consideration the fact that it is often effortlessly deployed in any economic discourse. For the validation of this, Knowles (1996: 791) is of the opinion that...

Any inspection of financial text and discourse will reveal that health metaphors occur and recur constantly. They are, however, routinely instantiated with respect to realia (sic) and situations where health is, at best, only an analogy or the imputation of an inherent property. For most "direct" communicators and readers, however, the expression health- and other germane lexis which, so to speak, revolves around that nucleus - paves the way to virtually totally satisfactory descriptive approximations to reality, accepted as such, either consciously or subconsciously, by the primary actors in the business of promulgating or absorbing news about the fortunes of financial markets.

By virtue of the above facts, this paper is concerned about health metaphors in Nigerian economic discourse, and also, taking into consideration, the obvious fact that the discursive role of health as a source domain is relatively unexplored in the economic discourse of Nigeria. 
Therefore, based on the forgoing, this study investigates a given conceptual domain, that is, health, and how metaphorical expressions that relate to this domain which is denoted as health metaphors are deployed as means of economic communication in the discourse on economy in the Nigerian print media. Specifically, this study examines the effects of health metaphorisation and how it is appropriated by journalists in shaping readers' perception of the Nigerian economy especially on economic issues that concern policy, budget and debt managements in The Punch, This Day and Business Day in 2003 to 2006.

\subsection{Health and Health Metaphors}

The conception of health is wide-ranging. The fact that the phenomenon has a positive facet and a negative dimension gives credence to its inclusiveness. The World Health Organisation, whose prime role is to direct and coordinate international health, elucidates that "health is a resource for everyday life, not the objective of living. Health is a positive concept emphasizing social and personal resources, as well as physical capacities", (Ottawa Charter for Health Promotion, WHO, Geneva, 1986:1).This notion is categorical about the basis that health is a resource that sustains human being's potentials and obligations in a society. On the other hand, the biomedical conception of health "focuses on the physical or biological aspects of disease and illness. It involves trying to diagnose, and treat illnesses and conditions once symptoms are present" (Health Care in Australia, 234).This perception about health shifts focus from the impression attributed to health by WHO, and tends towards ill-health being engendered by biological determinants. Nevertheless, beyond the consideration of the concept of health from two different sides of a coin, Boyd (2000) asserts that value judgments play crucial role in ascertaining what health is. Boyd (2000:12) stresses further that "there is, as it were, a common core of ideas about what... health is. But beyond that common core, our conceptions of disease and health begin to get fuzzy."Then, at this point, it is of great consequence to state that the abstract nature of health necessitates its characteristic vagueness and indefiniteness, but through the aid of metaphor a definite view of health can be derived. Barker (2000:97) already signals this idea when he states: “...metaphor serves as a linguistic anchor for our confused attempts to understand a potentially ineffable phenomenon."

Health, with metaphor, has been deployed to comprehend itself, and also to understand a number of other human concepts such as wealth, socio-economic concepts, morality, and love. Lakoff and Johnson (1999), as a case in point, delineate morality in terms of health (WELL-BEING IS HEALTH). According to them (278), "health, for most people, plays an important role in their living a full and happy life. It is not surprising; therefore, that there exists a basic metaphor of Well-Being Is Health, by which we understand moral well-being...." In a similar vein, health metaphor is also wellpreserved in the discernment of economy, a human concept which is the major focus in this paper. In this regard, Boers (1999) examines physical setting as a contributing factor for metaphor variation using economy as a target domain and health as the source domain. Precisely, Boers investigates health-related metaphors in the conceptualisation of economy in The Economist within a selected period of ten years; with his study confirming the frequency of health metaphor between the months of December and March for the ten years considered. In a related study, Boers and Demecheleer (1995) investigate health metaphor (including path and war metaphors) in western economic discourse advocating a free market ideology. At first, they observe the persuasive use of the metaphors in the opinion articles of The Economist, and secondly, they consider the relative frequencies of occurrence of the three metaphorical models across three languages: English, Dutch and French; with samples retrieved from newspaper editorials taken from The Financial Times. Boers and Demecheleer (1995:124) indicate that health metaphor "ensures lexical cohesion within the discourse, despite the apparent variety of expression." Apart from this, health metaphor offers potential bias for human reasoning about economics. According to them, "one's physical health is precious and consequently health care should be high on one's list of priorities in life. This inference may be preserved in the conception of economics under this metaphor" (124). Lastly, their findings reveal the frequencies of health metaphor, and the other two in the three languages examined. They argue that with the close relationship of English, Dutch and French, together with the global nature of economics, it would be unusual if health metaphor and the other two are completely absent from the samples. Urbonaite and Šeškauskienė (2007)probe into health metaphor in the English and Lithuanian political and economic discourse using two quality papers, Veidas and VersloZinios and two magazines in English and Lithuanian, The Economist and the Financial Times. Their analysis shows 
that "health metaphors are twice as frequent in English; however, both languages are equally prone to conceptualise political and economic difficulties in terms of health problems" (68). They, eventually, submit that socio-economic discourse is conceptualised in accordance with the universal/ anthropocentric parameter of the cognitive linguistic theory of metaphor and has preserved some culture-specific features.

A number of studies have examined metaphors in the Nigerian media public discourse but without focus on economic discourse, and decisive concentration on health metaphor contained therein. Typical examples are Chiluwa (2007) who investigates metaphors of power and corruption in media discourse. With this, he affirms that both metaphors of power and corruption are engaged discursively in media stories to sensitize, motivate and mobilize people towards social change. He concludes that metaphors are an effective means of communicating reality and issues of national development. Ezeifeka (2013) examines conventional metaphors used strategically by the Guardian newspaper in reporting events on the Nigerian Union of Teacher's industrial action that pertained to Teachers' Salary Scale (TSS) of June and July 2008. The paper reveals that the newspaper makes use of negative metaphors (such as sacrifice, rewardinheaven, villain, victim, war, wild animal, dead issue, $\operatorname{cog}$ in the wheel, etc. against group with limited access to societal power and means of communication) to veil its inadvertent ideological solidarity with the power elite in its attempt to act out its ombudsman position in the teachers' demand. Ezeifeka therefore brings to the fore the pervasiveness and negative effects of such metaphors in media reporting. In a related research to that of Chiluwa (2007), Isyaku et al (2016) conduct a study on corruption metaphors in the online news of Nigeria, Iraq and Malaysia so as to ascertain how the media of the different countries conceptualise the notion of corruption. According to them, corruption is conceptualised as war and man in Nigeria, Iraq, as culture, war and cancer, and in Malaysia, as orientation, virus and war. They, therefore, infer that all the countries perceive corruption as war which needs to be embattled because of its evil nature. From the gender perspective, Ahmed (2018) analyses metaphors used to describe women in opinion writings on gender by women writers in the Nigerian newspaper. The study submits that Nigerian women still make use of metaphors (like commodities, force, home managers, weaker sex, animals, plants, building materials, machines and farmlands) which sustain gender ideology, that is, male dominance and female subordination; which to a reasonable extent reveals the cognitive acceptance and consent to patriarchal hegemony of some Nigerian female authors of opinion articles. Ahmed, in conclusion, avows that the perception and description of the gendered self through metaphors in relation to others can be assisted or constrained by the dominance of gender ideology in human society.

From the Nigerian-resident scholarly works reviewed, metaphor has been projected to be a veritable conceptual and linguistic resource in the public discourse in the media, especially in the domain of socio-political and gender issues. Predominantly, power, corruption and gender related metaphors have resonated in these works. However, negligible research has been devoted exclusively to the subjects of health metaphor and the Nigerian economy. On the account of this hiatus, this study, therefore, is with the goal to contribute to the knowledge of health metaphors deployed by journalists to conceptualise the Nigerian economy; thereby adding to works on metaphors in Nigerian public discourse.

\section{THEORETICAL BACKGROUND}

The Conceptual Metaphor Theory (CMT) is predicated on the conception that "metaphor is pervasive in everyday life, not just in language, but in thought and action" (Lakoff and Johnson, 1980:454).This, in fact, comes as a response to the hallowed status given to metaphor as the preserve of poets, an extraordinaire device of genus; and a characteristic of language. Lakoff and Johnson (1980) redirect the notion of metaphor by affirming that "our ordinary conceptual system, in terms of which we both think and act, is fundamentally metaphorical in nature." Consequently, metaphor is now seen as a phenomenon that is part of everyday human speech and human cognition.

With the status of metaphor as human property, Conceptual Metaphor Theory holds that "the essence of metaphor is understanding and experiencing one kind of thing or experience in terms of another" (Lakoff and Johnson, 1980:455). Given this description, metaphor is considered an expression with two conceptual domains (knowledge fields) where one is understood in terms of the other. According to Kövecses (2010:4), "a convenient shorthand way of capturing this view of metaphor is the 
following: conceptual domain A is conceptual domain B, which is what is called a conceptual metaphor." These two domains have special names: source and target domains. The source is the readily understood area of human concrete experience while the target is the abstract non-delineated human experience understood through the source. The target domains, as Tilley (1999) states, "are abstract domains, frequently of the internal mental and emotional world or unseen and unknown domains of the physical world." This entire process, which is, sourcing for target through source means cross-domain mapping in the neural systems. This mapping, according to Lakoff $(1980,2003$, 2008), is systematic (because there is a set of correspondences between the two domains) and selective (because only a part of the source is mapped unto the target and only a part of the target is highlighted in the mappings from the source). For example, in the conceptual metaphor: ECONOMY IS A SICK HUMAN BEING, it is apparent that vital vantage points such as "death" or "being morgued" are hidden while the "passive state", as a result of illness is highlighted.

Significantly, Conceptual Metaphor Theory takes metaphor as a cognitive tool which is an integral part of human existence that helps in defining reality. And as Gibbs (2008:3) rightly emphasises, "metaphor is not simply an ornamental aspect of language, but a fundamental scheme by which people conceptualise the world and their own activities."

Therefore, in the light of this theoretical background, health metaphor in the discourse on the Nigerian economy is considered a conceptual (cognitive) phenomenon. It is judged conceptual on the account that it structures our conceptual system and gives certain perception of the status of the Nigerian economy during the period considered here. This argument will be substantiated currently.

\section{Data And Methodology}

The data for this paper were feature articles on the Nigerian economy. The rationale for their selection lies in the fact that they constituted critical macroeconomic issues about the economy of Nigeria, and were recurrent subjects of economy in the Nigerian mass media. These were matters on debt management, policy management and budget management. These articles were derived from three purposively selected Nigerian newspapers: Business Day, The Punch and This Day, which had relevance, wide circulation and adequate space for economic reporting in Nigeria. In total, 15 feature articles with average length of 1,633 words each, and published between 2003 and 2006 were sampled. The chosen period 2003 to 2006 is significant in view of the fact that it was the time President Obasanjo decided to focus harder on reforming Nigeria's faltering economy; and apart from this, it was the era the economy was being rescued from the harvest of ruinous policies of successive military administration. Consequently, based on the unpleasant economic situation of this period, health as a source domain was purposefully considered because it is effortlessly productive of linguistic representations in relation to the target domain of the Nigerian economy.

For the analysis, this paper engaged in qualitative analysis, and did not attempt to do any quantitative inquiry of the data gathered. In the analysis, health-related metaphorical expressions that relate to the target domain, the Nigerian economy, were identified manually, for instance, "The sick and bedridden Nigerian economy, no doubt, has clear complications..." (BD, 6 April, 2005:19). Next, metaphorical words such as sick, bedridden, complications, among others were identified. Then concurrently, the underlying conceptual metaphors were identified.

As a final point here, this paper adopted a few notions of abbreviations. First of all, when excerpts are presented in the analysis section, the names of the newspapers that they derive from have been abbreviated in the following manner: Business Day - BD, The Punch - PU and ThisDay - TD. Also, in accordance with the traditions of cognitive linguistics, and following the style conventions employed by Lakoff and Johnson (1980), the upper case was used in this paper to show the conceptual metaphors that underlie metaphors deployed by the print media in the representations of the Nigerian economy. In addition to this, the sampled metaphors under discussion in a given stretch of texts were represented in italics; if other metaphors occur in the same stretch of text but are not relevant to the discussion at the point, they do not appear in italics. Lastly, the target is also emboldened in such texts.

\section{Data Analysis}

\subsection{Conceptualising the Nigerian Economy from 2003 to 2006}

In 1999, a major enterprise that required the devotion of the Obasanjo administration was the Nigerian economy. This was consequent upon the fact that the sixteen years of successive military rule in 
Nigeria had a devastating effect on the economy. During these sixteen years, adequate planning was not given to the Nigerian economy and the body of the Nigerian press which would have occasioned resistance was repressed from the truth about the Nigerian economy. Nevertheless, with the emergence of a democratic rule in Nigeria in 1999, the Nigerian Press enjoyed fairly unfettered freedom. At this period, articles, features, editorials, among others, expressing valid facts about the economy of Nigeria occupied the media. The tempo of the state of the Nigerian economy media reports got amplified when the Obasanjo administration intensified commitment towards economic reforms in 2003. Interestingly, while the media present the Nigerian economy, they respond to the call of human conceptual system which is metaphorical in nature. Through striking health metaphors, conditioned by the status quo in Nigeria, this salient national issue was presented both in the electronic and in the print media.

\subsection{Health Metaphor of the Nigerian Economy from 2003 to 2006}

Health is associated with life expectancy and life quality (Boers and Demecheleer 1997). This association is positive, but it becomes negative when health is associated with illness, pain and even death. Physical negative health does not come suddenly; it often comes gradually with a noticeable unhealthy mental state. In this paper, this form of health deterioration is observed. Here, the Nigerian economy is conceptualised as a human being whose waning health traverses emotional illness to physical bodily ailment. This is presented in the conceptual metaphors below.

\section{The Bad State Of The Nigerian Economy Is The Bad State Of A Human Being}

This conceptual metaphor is a pungent personification employed by the media to describe the Nigerian economy within the period 2003 to 2006. The Nigerian economy is presented in the light of a human being, affected by deficient positive reinforcement and weakened by negative reinforcement. This conceptualisation becomes evident, for instance, from the following excerpts:

1. ...the economy was still depressed especially when assessed in terms of key policy thrusts and targets as enunciated in the 2005 federal budget. (PU, 20 May 2005:20)

2. All kinds of figures, in most cases, confusing and conflicting were being bandied all over the place regarding the exact amount of the debt overhang. External reserves by 1999 was $\$ 4.99$ billion and the economylay prostrate. (BD, 12 August, 2005:21)

3. The state of the Nigerian economy is the single most important issue today. It is the one issue which has kept citizens awake at night and worried during the day. (TD, 14 January 2004:10)

Depressed human beings are undeniably those set of people who experience negative support in one way or the other. With such experience, they tend to suffer insomnia, fatigue, hopelessness and probably nurse or being led to suicidal ideation. When these characteristics are mapped unto the domain of economics, it means that the economy lacks the exact policies or viable budget or it reeks in debt. As it could be lucidly seen, the excerpts above reveal the health related terms used to build the conceptual metaphor of BAD STATE OF A HUMAN BEING that depicts the bad state of the Nigerian economy. For instance, the attributive adjective, depressed, used by PU in excerpt 1 evokes a weak and an unresponsive Nigerian economy. As it is signalled by Kanter et al (2008:3), depression "appears to denote a feeling of heaviness, of being pressed down that is also referred to as sad, blue or simply down". This human state of despair often engendered by denial gives insight to the domain of the Nigerian economy as an economy denied the "key policy trust". A comparable metaphorisation is the utilisation of layprostrate by BD. To lie prostrate is a human physical orpsychological depressed state caused by certain human negligence. Mapping this unto the Nigerian economy further gives credence to its alarming state. A state threatened by huge unprecise debt, and paltry external reserve. According to Chow (2010:227), "the performance of an economy is often described as a cycle with four stages, namely depression, recovery, boom and recession". In his words, "a 'period of decline' implies that the economy was going through the stages of either recession or depression". As for the Nigerian economy, it is practically going through depression because its performance has been enfeebled due to lack of worthwhile policies and bad debt. This unpleasant state of the Nigerian economy so metaphorically portrayed through depressed and lay prostrate, has to certain levels 
prompted anxiety among Nigerians as presented in excerpt 3 by TD. This metaphorical representation complements that of PU and BD because when an individual is depressed, people around such an individual tend to keep vigil, and maintain a state of perturbation.

Lakoff and Johnson (1980:462) are of the opinion that "serious illness forces us physically to lie down". For a human being in a state of depression, and as a result lay prostrate, if not given the immediate attention, such situation may snowball into a sickening or ailing human being as it is found below.

\section{The Nigerian Economy Is A Sick Human Being/Patient}

In 2003 through 2006, the media, at some point, further underscored the precarious nature of the Nigerian economy through health metaphors which allow a better comprehension of the Nigerian economy in human terms. These metaphors employ personification, which is a way of ascribing human features to something which is nonhuman in order to explain it and express our reactions toward it (Lakoff and Johnson 1980). Lakoff and Johnson (1980) acknowledge that personification does not only enable us to visualise a phenomenon as a person endowed with human objectives, goals and motives, however, it makes possible the selection of different aspects of a person or ways of looking at a person in a certain metaphor. This is the case with the Nigerian economy as well, which in line with the instantiated examples observed in our data, is further personified as a sick human being or a patient. The conceptual metaphor thus represented is THE NIGERIAN ECONOMY IS A SICK HUMAN BEING/PATIENT, which presents the Nigerian economy as a phenomenon that, needs urgent attention. Consider the following excerpts:

4. The sick and bedridden Nigerian economy, no doubt, has clear complications. It has a fractured left leg in addition to the general bodily debilitation. It is also quite likely that the patient has been in the hospital for a long time. There is a challenge for the physician as to what therapy should be appropriate in the circumstances. (BD, 6 April, 2005:19)

5. The Chairman and founder of Akinola Williams Deloitte, Mr.Akinola Williams, has said that the Nigerian economy was sick and needs treatment so that it could come back to life.

(PU, 2 August 2004:19)

6. A sickeconomy is like a sick person. In the normal order of things, the first step is a diagnosis of the problem, followed by a determination of the severity of the ailment based on a set of facts and data. It is only after this that the correct medication can be prescribed and the dosage appropriate to the intensity of the disease applied. In the absence of identifying the nature and severity of the problem, it is a wonder how the economic technocrats arrived at their findings that to restore the economy to health would require, at least, a five percent annual GDP growth rate for 10 years. (TD, 25 August, 2003:21)

Sontag (1978:3) is of the view that "illness is the night-side of life, a more onerous citizenship. Everyone who is born holds that dual citizenship, in the kingdom of the well and in the kingdom of the sick". This human attribute, (citizenship of the kingdom of the sick) so described by Sontag, is preserved in the Nigerian economy as evident in the immediate excerpts. The Nigerian economy is depicted as experiencing health challenges that only human beings could experience as a result of malnourishment, neglect, unfavourable weather condition or environment. This suggests that the Nigerian economy istotally in dearth of worthwhile policies, comprehensive budgeting and top government participation. In excerpts 4, B Dconstrues the Nigerian economy as a sick human being that has been in the hospital for a very long period of time as a result of health challenges that range from fractured legto entire body debilitation. Worst of all is the fact that the physician attending to the Nigerian economy does not have any clue to the appropriate therapy that may likely salvage the Nigerian economy from such death-defying state of health. This implies that the Nigerian economy is in such inactive state because of unworkable policies, crippling debt and the fact that the Nigerian government lacks the logicality to make the economy active. This appraisal of the Nigerian economy by $\mathrm{BD}$ also intersects with the report made by PU in excerpt 5 where human state of illness is mapped 
unto the Nigerian economy. Excerpt 6, on the other hand, correspondingly confirms that the Nigerian economy is sick. However, it gives some processes that could be explored in order to rescue the Nigerian economy from perdition. In the same way as a human being, the Nigerian economy will go through diagnosis(auditing) so as to ascertain the nature of ailment(impracticable policies, debt etc.), and to determine the right medication(feasible policies, analytical leadership etc.) and dosage (required policies, the right economic managers etc.) for treatment(subsidies, zero tolerance for corruption, government total involvement etc.).

The various health metaphors deployed in respect of the Nigerian economy are deliberate metaphors (Steen, 2011) deployed by the media not only to induce the peception of the Nigerian economy, but also to serve as persuasive devices as regards the lamentable condition of the Nigerian economy between 2003 and 2006.

\section{CONCLUSiON}

Articles about the Nigerian economy that span policy, budget and debt managements in 2003 to 2006, in the three Nigerian newspapers used for this paper, namely, Business Day, Punch and This Day engage health metaphors to depict the Nigerian economy. As cognitive tools, the health (conceptual) metaphors (THE BAD STATE OF THE NIGERIAN ECONOMY IS THE BAD STATE OF A HUMAN BEING \& THE NIGERIAN ECONOMY IS A SICK HUMAN BEING/PATIENT) identified offer insight into the domain of the Nigerian economy. These metaphors portray the deterioration and inactiveness of the Nigerian economy, and with these readers are persuaded on what state the Nigerian economy is. Health metaphor performs multifarious functions in the construction and interpretation of economic issues. It is not an extraordinaire device of genus, but the sequence of motivated cognitive and device used by Nigerian journalists in rendering contemporary Nigerian issues.

\section{REFERENCES}

[1] Ahmed, Umar. 2018.Metaphor in the construction of gender in media discourse: analysis of metaphors used to describe women in Nigerian newspapers. International Journal of Gender and Women's Studies, 6 , (1) 88-99.

[2] Barker, Phill. 2000. Working with the metaphor of life and death. Med Ethics: Medical Humanities, 26, 97-102.

[3] Boers, Frank .1997. No pain, no gain in free market rhetoric: a test for cognitive semantics? Metaphor and Symbol 12(4): 231-241.

[4] Boers, Frank. \& Demecheleer, Murielle .1995.A Few Metaphorical Models in (Western) Economic Discourse. In W-A Liebert, G. Redeker and L. Waugh (eds.), Discourse and Perspective in Cognitive Linguistics115-129. Amsterdam: John Benjamins.

[5] Boyd, Kenneth .2000. Disease, illness, sickness, health, healing and wholeness: exploring some elusive concepts.Med Ethics: Medical Humanities, 26, 9-17.

[6] Charteris-Black Jonathan .2004.Corpus approaches to critical metaphor Analysis. London: Palgrave Macmillan.

[7] Chiluwa, Innocent .2007. Metaphors of power and corruption in media discourse in Nigeria. Benson Idahosa University Discourse, 2, 1-12.

[8] Chow, Meiyung .2010. A comparative study of the metaphor used in the economic news articles in Britain and Hong Kong. University of Birmingham PhD Thesis.

[9] Ezeikefa, Chinwe. 2013. Use of metaphor in Nigerian newspaper reports: a critical perspective. Cadaad, 6, 174-192.

[10] Gibbs, Raymond. 2008. Image schemas in conceptual development: what happened to the body? Philosophical Psychology, 21, 231-239.

[11] Health Care in Australia. http://www.wiley.com/legacy/Australia/Landing_Pages/KC_VCE_ H\&HD_U3\&4_4E_c06_web(Accessed July 10, 2018).

[12] Isyaku, Hassan et al .2016.A study of the use of corruption metaphors in the online media of Nigeria, Iraq and Malasia. Journal of Applied Linguistics and Language Research, 3, 68-84.

[13] Kanter, Jonathan et al. 2008. The nature of clinical depression: symptoms, syndromes, and behavior analysis. The Behavior Analyst, 31, 1-21.

[14] Knowles, Franci.1996. Lexicographical aspect of health metaphors in financial text.Euralex 96 Proceedings, 789-795. 
[15] Koller, Veronica .2003. Metaphor clusters in business media discourse: a social cognition approach. University of Vienna PhD Thesis.

[16] Kövecses, Zoltan .2010. Metaphor: a practical introduction. New York, NY: Oxford University Press.

[17] Kövecses, Zoltán. .2005.Metaphor inculture: universality and variation. New York: Cambridge University Press.

[18] Lakoff, George \& Johnson, Mark .1980. Metaphors we live by. Chicago: University of Chicago Press.

[19] Lakoff, George \&Johnson, Mark .1999.Philosophy in the flesh-the embodied mind and its challenge to western thought. New York: Basic Books.

[20] Lakoff, George .2008. The neural theory of metaphor. In Ray Gibbs (ed.), The Cambridge Handbook of Metaphor and Thought, 17-38. Cambridge University Press, New York.

[21] Ottawa Charter for Health Promotion, WHO, Geneva, 1986.

[22] Silaški, Nadezda\&Kilyeni, Annamaria .2011. The money is a liquid metaphor in economic terminology-a contrastive analysis of English, Serbian and Romanian. Professional Communication and Translation Studies, 4, (1-2), 63-72.

[23] Sontag, Susan .1978. Illness as metaphor. Toronto: McGraw-Hill Ryerson Ltd.

[24] Steen, Gerald .2011. When is metaphor deliberate? Department of Language and Communication, VU University of Amsterdam.

[25] Tilley, Christopher.1999. Metaphor and material culture. Social Archaeology. Blackwell Publishers, Oxford.

[26] Tomoni, Bianca .2012. Conceptual Metaphors in Financial Discourse: the Romanian Way of Thinking, Speaking and Writing Finances in Selected Papers from UK-CLA meetings http://ukcla.org.uk/ proceedings, $1,146-163$.

[27] Urbonaite, Justina\&Šeškauskienè, Inesa .2007.Health metaphor in political and economic discourse: a cross-linguistic analysis. Studies about Languages, 11, 68-73.

[28] White, Michael .2003. Metaphor and economics: the case of growth. English for Specific Purposes 22,131-151.

\section{AUTHORS' BIOGRAPHY}

Tolulope Abisodun Oluremi (Ph.D), is a Lecturer at the Department of English and Literary Studies, Osun State University, (Ikire Campus) Nigeria. His research areas include Discourse Pragmatics, Stylistics and Cognitive Linguistics.

Ife FiyinfoluAjepe (Ph.D), is a Lecturer at the Department of English and Languages, AfeBabalola University, Ekiti State Nigeria. Her research areas include, Multimodal Communication, Discourse Analysis, and Applied Linguistics.

Citation: Tolulope Abisodun Oluremi (PhD), Ife Fiyinfolu Ajepe (PhD). "Health Metaphor in Nigeria Economic Discourse" International Journal of Managerial Studies and Research (IJMSR), vol 9, no. 9, 2021, pp. 13-20. doi: https://doi.org/10.20431/2349-0349.0909002.

Copyright: () 2021 Authors. This is an open-access article distributed under the terms of the Creative Commons Attribution License, which permits unrestricted use, distribution, and reproduction in any medium, provided the original author and source are credited. 